\title{
Growth and Structure of Pure ZnO Micro/Nanocombs
}

\author{
Tengfei Xu, ${ }^{1,2}$ Pengfei Ji, ${ }^{2}$ Meng He, ${ }^{2}$ and Jianye $\mathrm{Li}^{1}$ \\ ${ }^{1}$ Department of Physical Chemistry, University of Science and Technology Beijing, Beijing 100083, China \\ ${ }^{2}$ National Center for Nanoscience and Technology, Beijing 100190, China \\ Correspondence should be addressed to Meng He, mhe@nanoctr.cn and Jianye Li, jyli@ustb.edu.cn \\ Received 19 September 2011; Revised 16 December 2011; Accepted 18 December 2011 \\ Academic Editor: Ting Zhu
}

Copyright ( $) 2012$ Tengfei Xu et al. This is an open access article distributed under the Creative Commons Attribution License, which permits unrestricted use, distribution, and reproduction in any medium, provided the original work is properly cited.

Comb-shaped $\mathrm{ZnO}$ micro/nanostructures were grown on copper substrate using a highly repeatable catalyst-free chemical vapor deposition method. The structure of the $\mathrm{ZnO}$ micro/nanocombs was analyzed, and the necking-down phenomena of the comb teeth was explained. The cathodoluminescence (CL) spectrum was measured on an individual $\mathrm{ZnO}$ comb, and a strong deep-level emission centered at about $520 \mathrm{~nm}$ was observed.

\section{Introduction}

$\mathrm{ZnO}$, with a wide bandgap of $3.37 \mathrm{eV}$ at room temperature and a high exciton binding energy of $60 \mathrm{meV}$, is a direct bandgap II-VI semiconductor with good performances. In the past decade, nano- $\mathrm{ZnO}$ has attracted considerable attention. A variety of $\mathrm{ZnO}$ nanostructures, nanowires [1], nanorods [2], nanoribbons [3], nanocombs [4], nanorings [5], nanohelices [6], and nanotetrapods [7], and have been discovered and reported. Among them, $\mathrm{ZnO}$ nanocombs consisting of a ribbon and an array of parallel nanorods perpendicular to the ribbon are of interest for nanocantilever arrays [4], laser arrays [8], nanocomb biosensors [9], and gratings [10].

So far, $\mathrm{ZnO}$ nanocombs have been synthesized mainly by thermal evaporation using $\mathrm{Zn}$ or $\mathrm{ZnO}$ usually mixed with graphite powers as precursors in a wide temperature range $\left(440^{\circ} \mathrm{C}-1350^{\circ} \mathrm{C}\right)[4,11-18]$. In most cases, Au was also used as the catalyst in the growth. The mechanism involved in generating $\mathrm{ZnO}$ nanocombs includes vaporsolid (VS) mechanism without any catalysts and vapor-solidliquid (VLS) mechanism directed by catalysts. Wang et al. [4] reported that the Zn-terminated (0001) polar surface is chemically active and can initiate a self-catalyzed effect that promotes the growth of comb-like arrays, while the Oterminated $(000 \overline{1})$ polar surface is inert in initiating growth. Chen et al. [16] reported that both VS and VLS mechanisms could explain the growth of $\mathrm{ZnO}$ comb-like structures.
Herein, a chemical vapor deposition (CVD) process using a precursor of mixed $\mathrm{ZnO}$ and graphite powders is carried out to grow comb-like $\mathrm{ZnO}$ micro/nanostructures. In the process, no catalyst is used and as well no catalyst particle is detected at the comb tip, indicating a VS mechanism in the growth of the $\mathrm{ZnO}$ comb-like structures. The absence of catalyst particle on the as-grown $\mathrm{ZnO}$ micro/nanocombs is an advantage to fabricate $\mathrm{ZnO}$ micro/nanodevices without the influence of impurity. This facile way for growing pure $\mathrm{ZnO}$ comb-shaped micro/nanostructures on a large scale will facilitate the broad applications of $\mathrm{ZnO}$ micro/nanocombs. At last, the structure and growth mechanism of the combshaped $\mathrm{ZnO}$ structures were discussed, and the CL properties of individual $\mathrm{ZnO}$ combs were investigated.

\section{Experimental Section}

The $\mathrm{ZnO}$ micro/nanocombs were synthesized in a tube furnace system [19] through a chemical vapor deposition (CVD) method. At first, a mixture of $\mathrm{ZnO}$ and graphite powders (weight ratio 2:1) was grounded and loaded into a quartz boat, which is placed at the center of a horizontal tube furnace. A clean $\mathrm{Cu}$ sheet without catalyst was used as a substrate and placed downstream of the source materials to collect the products. Argon, with a flow rate of $30 \sim 70 \mathrm{sccm}$ (standard cubic centimeters per minute), was used as the carrier gas. Then, the source materials were heated up to $1000^{\circ} \mathrm{C}$ with a heating rate of $45^{\circ} \mathrm{C} / \mathrm{min}$. The substrate 


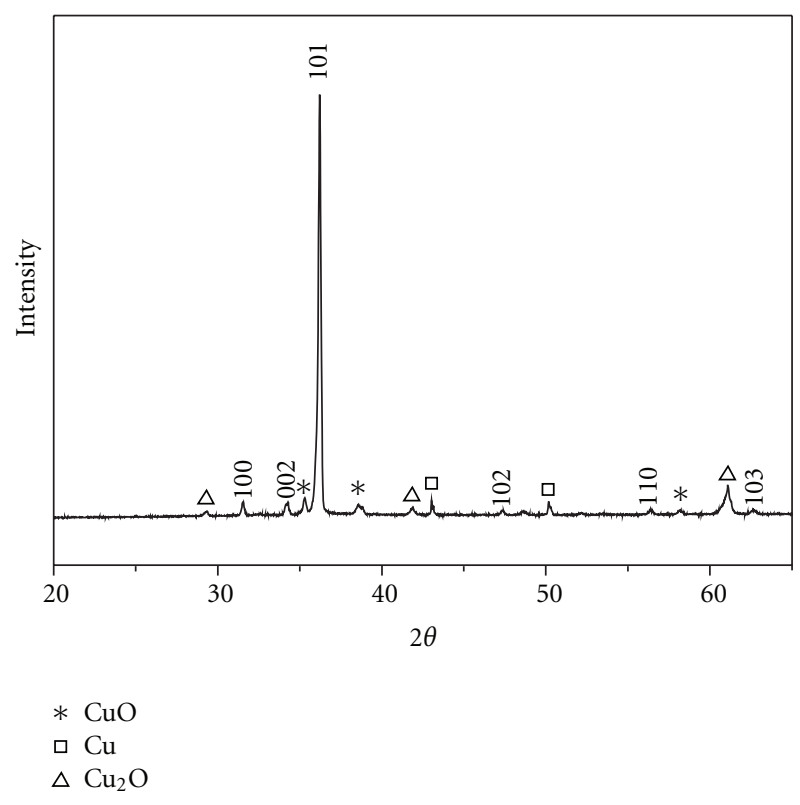

FIGURE 1: XRD pattern of as-prepared $\mathrm{ZnO}$ comb-like structures grown on $\mathrm{Cu}$ substrate.

temperature is $950^{\circ} \mathrm{C}$ due to the temperature gradient of the tube-furnace. The pressure was kept at 1 atm during the reaction. The growth was maintained for $90 \mathrm{~min}$. Then, the furnace was cooled down to room temperature, and white products were found covering the $\mathrm{Cu}$ substrate.

The as-synthesized products were characterized by $\mathrm{X}$ ray diffraction (XRD, Panalytical X'pert PRO diffractometer), scanning electron microscopy (SEM, Hitachi S-4800), energy-dispersive X-ray (EDX) spectroscopy and transmission electron microscopy (TEM, Tecnai G ${ }^{2}$ F20 U-TWIN). Cathodoluminescence spectrum of an individual comb-like structure was recorded using an in situ optical-electrical measurement system based on a Keithley 4200 semiconductor characterization system and an FEI XL30-SFEG SEM equipped with 4 Kleindiek MM3A nanomanipulators, and the current intensity of electron beam was less than $1 \mathrm{nA}$. More details about the in situ optical-electrical measurement system can be found in [20].

\section{Results and Discussion}

$\mathrm{X}$-ray powder diffraction pattern of the as-synthesized $\mathrm{ZnO}$ micro/nanocombs was shown in Figure 1. Reflections from wurtzitic $\mathrm{ZnO}$ could be readily identified and a strong preferred orientation of (101) plane was evidenced. Some weak reflections corresponding to $\mathrm{Cu}, \mathrm{Cu}_{2} \mathrm{O}$, and $\mathrm{CuO}$ were also observed and ascribed to the $\mathrm{Cu}$ substrate.

Figure 2 is an energy-dispersive $\mathrm{X}$-ray spectrum measured on the comb-like structures, and it reveals that only $\mathrm{Zn}$ and $\mathrm{O}$ can be detected and $\mathrm{Cu}$ or other elements are absent. Therefore no particles of $\mathrm{Cu}, \mathrm{Cu}$ oxides, or $\mathrm{Cu}$ alloys contaminate the comb-shaped structures; the $\mathrm{Cu}, \mathrm{Cu}_{2} \mathrm{O}$, and $\mathrm{CuO}$ identified by XRD should come from the substrate.

Typical SEM images are given in Figures 3(a)-3(c). Some $\mathrm{ZnO}$ comb-shaped structures accumulating over the

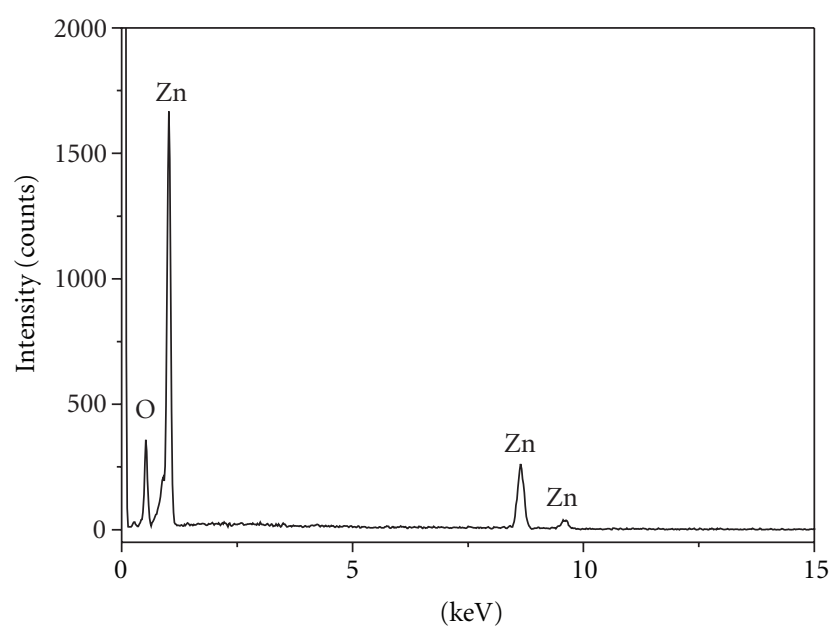

FIGURE 2: EDX spectrum of the $\mathrm{ZnO}$ comb-like structures.

substrate can be seen from Figure 3(a). Figure 3(b) presents the details of the morphology of an individual $\mathrm{ZnO}$ comb. The comb-like structure has teeth with a length up to $20 \mu \mathrm{m}$ and a thickness of several hundreds of nanometers. All the teeth stand parallel to one another on one side of ribbonlike stems. The stems are ribbons with a thickness of several hundreds of nanometers and a length of several tens of micrometers. The width of the ribbon is almost the same along the growth direction, which is different from the bladelike structures reported in previous literature $[11,16]$. Shown in Figure 3(c) is another kind of $\mathrm{ZnO}$ comb-like structures forming on the $\mathrm{Cu}$ substrate. The width of the tooth shrinks drastically from several $\mu \mathrm{m}$ at its root to about $300 \mathrm{~nm}$ at its sharp tip. The teeth are uniform in length and width in general. The distance between two adjacent teeth is about $2 \mu \mathrm{m}$.

The $\mathrm{ZnO}$ micro/nanocombs were further characterization by TEM. Shown in Figure 4(a) is a low-magnification image of a comb-like $\mathrm{ZnO}$ structure, and the selected area electron diffraction (SAED) pattern obtained from the stem part of the comb-like structure is given as an inset. Presented in Figure $4(\mathrm{~b})$ is an image of the root part of the teeth at higher magnification and SAED pattern taken from a tooth. The identical SAED patterns obtained from different parts of the comb-like structure indicates that the entire particle is a single crystal. SAED patterns agree well with [100] zone axis of wurtzitic $\mathrm{ZnO}$, confirming the results of XRD and EDX analyses. Though [001] cannot be distinguished explicitly from $[00 \overline{1}]$ direction with only SAED pattern, we assume that the direction from stem ribbon to the tip of the tooth is [001] in reference to [4]. The teeth of the comb-like structure grow along $c$-axis while the stem ribbon grows along [120] direction with $(2 \overline{1} 0)$ planes as top and bottoms surfaces. Different from the comb structures reported here, the stem ribbons of comb-like structures synthesized by Wang et al. grow along [100] direction with (010) planes as top and bottom surfaces. The necking down of the teeth is frequently observed for our comb-like structures, and interestingly, the positions of necking down are quite uniform for teeth of the 

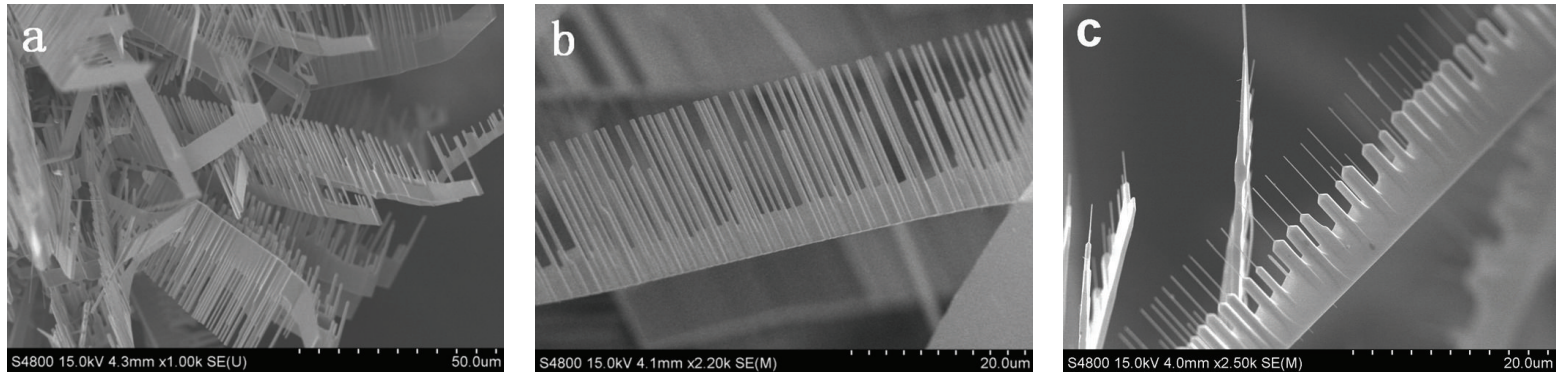

FIGURE 3: Typical SEM images of the comb-like $\mathrm{ZnO}$ structures.

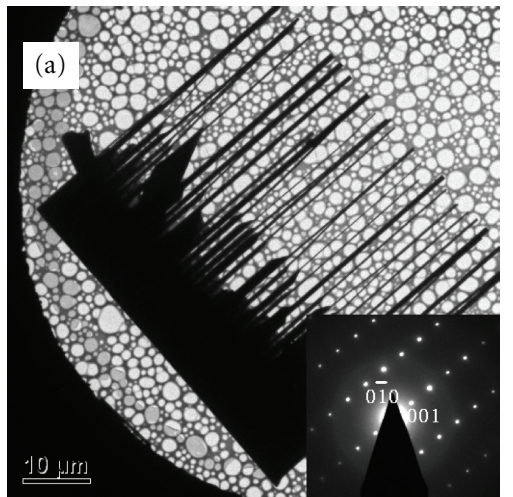

(d)

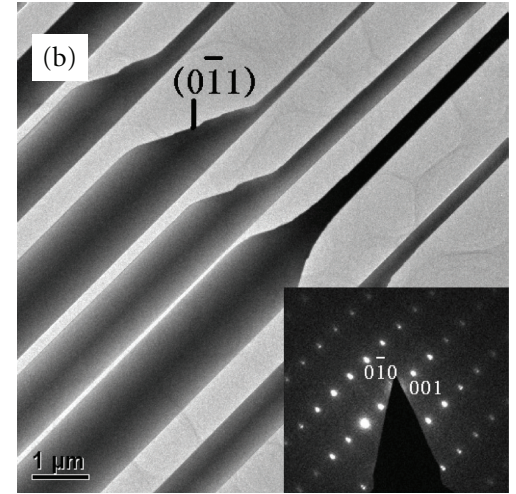

(011) (011)
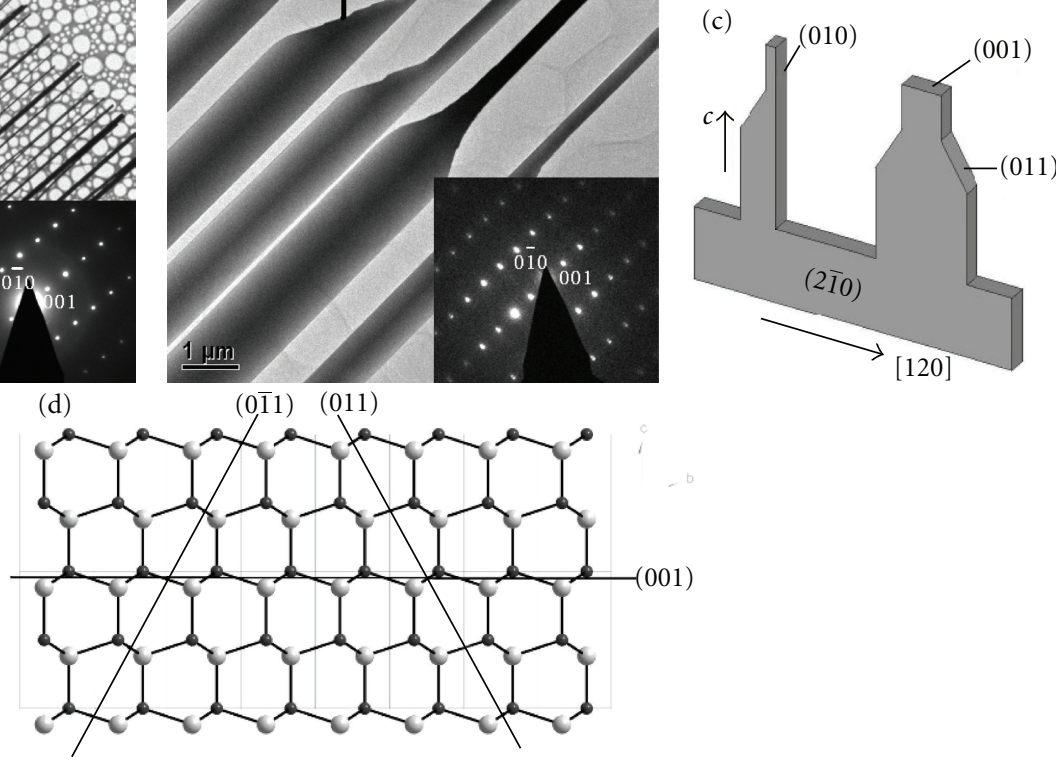

$\mathrm{O}-2$
$\mathrm{Zn}+2$

FIGURE 4: (a) TEM image of a $\mathrm{ZnO}$ comb, showing the distinct arrays of teeth on one side. The inset is the SAED pattern taken from the stem ribbon. (b) TEM image of the root part of the teeth at higher magnification and the corresponding SAED pattern. (c) Schematic models of the comb-like structure observed by TEM. (d) A projection of wurtzite-type $\mathrm{ZnO}$ along [100] direction highlighting its polar planes (001), (011), and $(0 \overline{1} 1)$.

same comb-like structure. The inclined facets occurring at the place where the teeth are necking down are $(0 \overline{1} 1)$ and/or (011), as shown in Figures 4(b) and 4(c). It is noteworthy that $(0 \overline{1} 1)$ and $(011)$ are polar planes, as indicated in Figure 4(d). We suggest that the necking down of the teeth is closely related with the polar planes of wurtzite-type $\mathrm{ZnO}$. Possibly, the surface energy of $(0 \overline{1} 1)$ and (011) polar planes are comparable with that of (001), the most wellknown polar planes for wurtzite-type structure. Fluctuation of experimental conditions during the growth can lead to that $(0 \overline{1} 1)$ and (011) surfaces are energy preferred over (001). Then, (011) and/or (011) facets will appear at the tips of the teeth. Clearly, nonpolar surfaces with low indices, such as $(010)$ and $(2 \overline{10})$ as well as their equivalents are more stable than polar ones. Hence, non-polar surfaces are preferred over polar ones to terminate the single crystalline teeth during the subsequent growth. When such a process happens, a necking down of the teeth will result, and sharper tips will be obtained. So the necking-down phenomena dominated by competition between polar surfaces and non-polar ones can be utilized to synthesize wurtzite-type structures with both sharp tips at nanoscale and thick roots in size of micrometers, which should be very desirable for some applications.

The CL spectrum measured on an individual $\mathrm{ZnO}$ comblike structure is shown in Figure 5. Only a broad and strong green emission band centered at $520 \mathrm{~nm}$ is observed, which is commonly seen in $\mathrm{ZnO}$ materials synthesized under oxygen-deficient conditions, such as the gas-phase produced nanowires [21]. The chemical and structural origins of the green luminescence from undoped $\mathrm{ZnO}$ are 


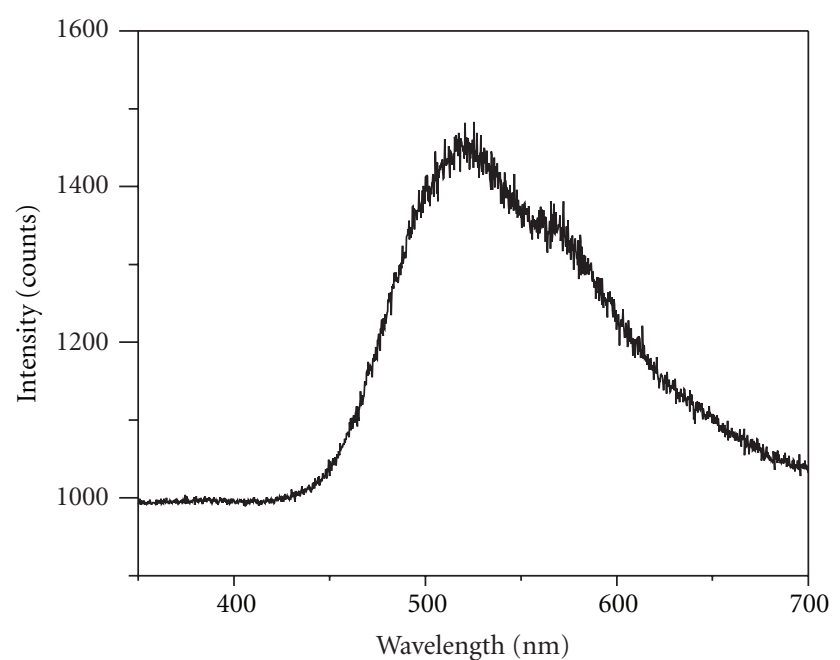

Figure 5: CL spectrum measured on an individual $\mathrm{ZnO}$ comb-like structure.

still a matter of debate $[22,23]$. In what is perhaps the most frequently cited explanation, electrons trapped in singly ionized oxygen vacancies recombine with valence band holes [24]. In another frequently cited explanation, electrons in the conduction band and/or shallow donor states recombine with holes that have been trapped in oxygen vacancies [25]. Compared to the strong green emission centered at $520 \mathrm{~nm}$, no near band edge emission of $\mathrm{ZnO}$ was found in Figure 5. The disappearance of the near ultraviolet (UV) band edge emission is due to the low electron beam (1 nA) of the CL measurement. Such a low electron beam generates few electron-hole pairs. Furthermore, a large number of excited electrons are trapped by oxygen vacancies, resulting in little recombination of electron-hole pairs. Thus, the near band edge emission peak of $\mathrm{ZnO}$ disappears.

\section{Conclusions}

In summary, $\mathrm{ZnO}$ micro/nanocombs have been successfully synthesized on $\mathrm{Cu}$ substrate without catalyst using a simple CVD method. The growth of the comb-like structures can be attributed to a VS mechanism. The structure of the $\mathrm{ZnO}$ micro/nanocombs was analyzed and the neckingdown phenomena of the comb teeth was explained. The $\mathrm{CL}$ spectrum was measured on an individual $\mathrm{ZnO}$ comb and only a broad strong green emission band was observed. This facile way for growing pure $\mathrm{ZnO}$ micro/nanocombs on a large scale will facilitate the broad applications of $\mathrm{ZnO}$ micro/nanocombs.

\section{Authors' Contributions}

T. Xu and P. Ji have equally contributed to this paper.

\section{Acknowledgments}

The authors thank the financial supports from the National Natural Science Foundation of China (21071016), the Fundamental Research Funds for the Central Universities of
China, Beijing Natural Science Foundation (2093038), and Scientific Research Foundation for the Returned Overseas Chinese Scholars, Ministry of Education of China. Mr. Z. Liu and Dr. M. Gao at Peking University are gratefully acknowledged for help in the CL measurements.

\section{References}

[1] M. H. Huang, S. Mao, H. Feick et al., "Room-temperature ultraviolet nanowire nanolasers," Science, vol. 292, no. 5523, pp. 1897-1899, 2001.

[2] J. Y. Li, X. L. Chen, H. Li, M. He, and Z. Y. Qiao, "Fabrication of zinc oxide nanorods," Journal of Crystal Growth, vol. 233, no. 1-2, pp. 5-7, 2001.

[3] Z. W. Pan, Z. R. Dai, and Z. L. Wang, "Nanobelts of semiconducting oxides," Science, vol. 291, no. 5510, pp. 19471949, 2001.

[4] Z. L. Wang, X. Y. Kong, and J. M. Zuo, "Induced growth of asymmetric nanocantilever arrays on polar surfaces," Physical Review Letters, vol. 91, no. 18, Article ID 185502, 4 pages, 2003.

[5] X. Y. Kong, Y. Ding, R. Yang, and Z. L. Wang, "Single-crystal nanorings formed by epitaxial self-coiling of polar nanobelts," Science, vol. 303, no. 5662, pp. 1348-1351, 2004.

[6] P. X. Gao, Y. Ding, W. Mai, W. L. Hughes, C. Lao, and Z. L. Wang, "Conversion of zinc oxide nanobelts into superlatticestructured nanohelices," Science, vol. 309, no. 5741, pp. 17001704, 2005.

[7] J. Y. Li, H. Peng, J. Liu, and H. O. Everitt, "Facile gramscale growth of single-crystalline nanotetrapod-assembled $\mathrm{ZnO}$ through a rapid process," European Journal of Inorganic Chemistry, no. 20, pp. 3172-3176, 2008.

[8] H. Yan, R. He, J. Johnson, M. Law, R. J. Saykally, and P. Yang, "Dendritic nanowire ultraviolet laser array," Journal of the American Chemical Society, vol. 125, no. 16, pp. 4728-4729, 2003.

[9] J. X. Wang, X. W. Sun, A. Wei et al., "Zinc oxide nanocomb biosensor for glucose detection," Applied Physics Letters, vol. 88, no. 23, Article ID 233106, 2006.

[10] Z. W. Pan, S. M. Mahurin, S. Dai, and D. H. Lowndes, "Nanowire array gratings with $\mathrm{ZnO}$ combs," Nano Letters, vol. 5, no. 4, pp. 723-727, 2005.

[11] C. X. Xu, X. W. Sun, Z. L. Dong, and M. B. Yu, "Self-organized nanocomb of $\mathrm{ZnO}$ fabricated by Au-catalyzed vapor-phase transport," Journal of Crystal Growth, vol. 270, no. 3-4, pp. 498-504, 2004.

[12] Y. H. Zhang, J. Liu, T. Liu, L. P. You, and X. G. Li, "Supersaturation-controlled synthesis of two types of singlesided $\mathrm{ZnO}$ comb-like nanostructures by thermal evaporation at low temperature," Journal of Crystal Growth, vol. 285, no. 4, pp. 541-548, 2005.

[13] Y. Zhang, X. Song, J. Zheng, H. Liu, X. Li, and L. You, "Symmetric and asymmetric growth of $\mathrm{ZnO}$ hierarchical nanostructures: nanocombs and their optical properties," Nanotechnology, vol. 17, no. 8, pp. 1916-1921, 2006.

[14] X. Li, C.-X. Xu, G.-P. Zhu et al., "Disc-capped $\mathrm{ZnO}$ nanocombs," Chinese Physics Letters, vol. 24, no. 12, pp. 34953498, 2007.

[15] U. Manzoor and D. K. Kim, "Synthesis and enhancement of ultraviolet emission by post-thermal treatment of unique zinc oxide comb-shaped dendritic nanostructures," Scripta Materialia, vol. 54, no. 5, pp. 807-811, 2006. 
[16] Y. X. Chen, M. Lewis, and W. L. Zhou, "Zno nanostructures fabricated through a double-tube vapor-phase transport synthesis," Journal of Crystal Growth, vol. 282, no. 1-2, pp. 85-93, 2005.

[17] Y. S. Lim, J. W. Park, S.-T. Hong, and J. Kim, "Carbothermal synthesis of $\mathrm{ZnO}$ nanocomb structure," Materials Science and Engineering B, vol. 129, no. 1-3, pp. 100-103, 2006.

[18] R. F. Zhuo, H. T. Feng, Q. Liang et al., "Morphologycontrolled synthesis, growth mechanism, optical and microwave absorption properties of $\mathrm{ZnO}$ nanocombs," Journal of Physics D, vol. 41, no. 18, Article ID 185405, 2008.

[19] J. Y. Li, L. S. Wang, D. B. Buchholz, and R. P. H. Chang, "Simultaneous growth of pure hyperbranched $\mathrm{Zn}_{3} \mathrm{As}_{2}$ structures and long $\mathrm{Ga}_{2} \mathrm{O}_{3}$ nanowires," Nano Letters, vol. 9, no. 5, pp. 17641769, 2009.

[20] C. Li, M. Gao, C. Ding et al., "In situ comprehensive characterization of optoelectronic nanomaterials for device purposes," Nanotechnology, vol. 20, no. 17, Article ID 175703, 2009.

[21] L. E. Greene, M. Law, J. Goldberger et al., "Low-temperature wafer-scale production of $\mathrm{ZnO}$ nanowire arrays," Angewandte Chemie, vol. 42, no. 26, pp. 3031-3034, 2003.

[22] J. V. Foreman, J. Li, H. Peng, S. Choi, H. O. Everitt, and J. Liu, "Time-resolved investigation of bright visible wavelength luminescence from sulfur-doped $\mathrm{ZnO}$ nanowires and micropowders," Nano Letters, vol. 6, no. 6, pp. 1126-1130, 2006.

[23] J. Y. Li, Q. Zhang, H. Peng, H. O. Everitt, L. Qin, and J. Liu, "Diameter-controlled vapor-solid epitaxial growth and properties of aligned $\mathrm{ZnO}$ nanowire arrays," Journal of Physical Chemistry C, vol. 113, no. 10, pp. 3950-3954, 2009.

[24] K. Vanheusden, W. L. Warren, C. H. Seager, D. R. Tallant, J. A. Voigt, and B. E. Gnade, "Mechanisms behind green photoluminescence in $\mathrm{ZnO}$ phosphor powders," Journal of Applied Physics, vol. 79, no. 10, pp. 7983-7990, 1996.

[25] A. Van Dijken, E. A. Meulenkamp, D. Vanmaekelbergh, and A. Meijerink, "The kinetics of the radiative and nonradiative processes in nanocrystalline $\mathrm{ZnO}$ particles upon photoexcitation," Journal of Physical Chemistry B, vol. 104, no. 8, pp. 1715-1723, 2000. 

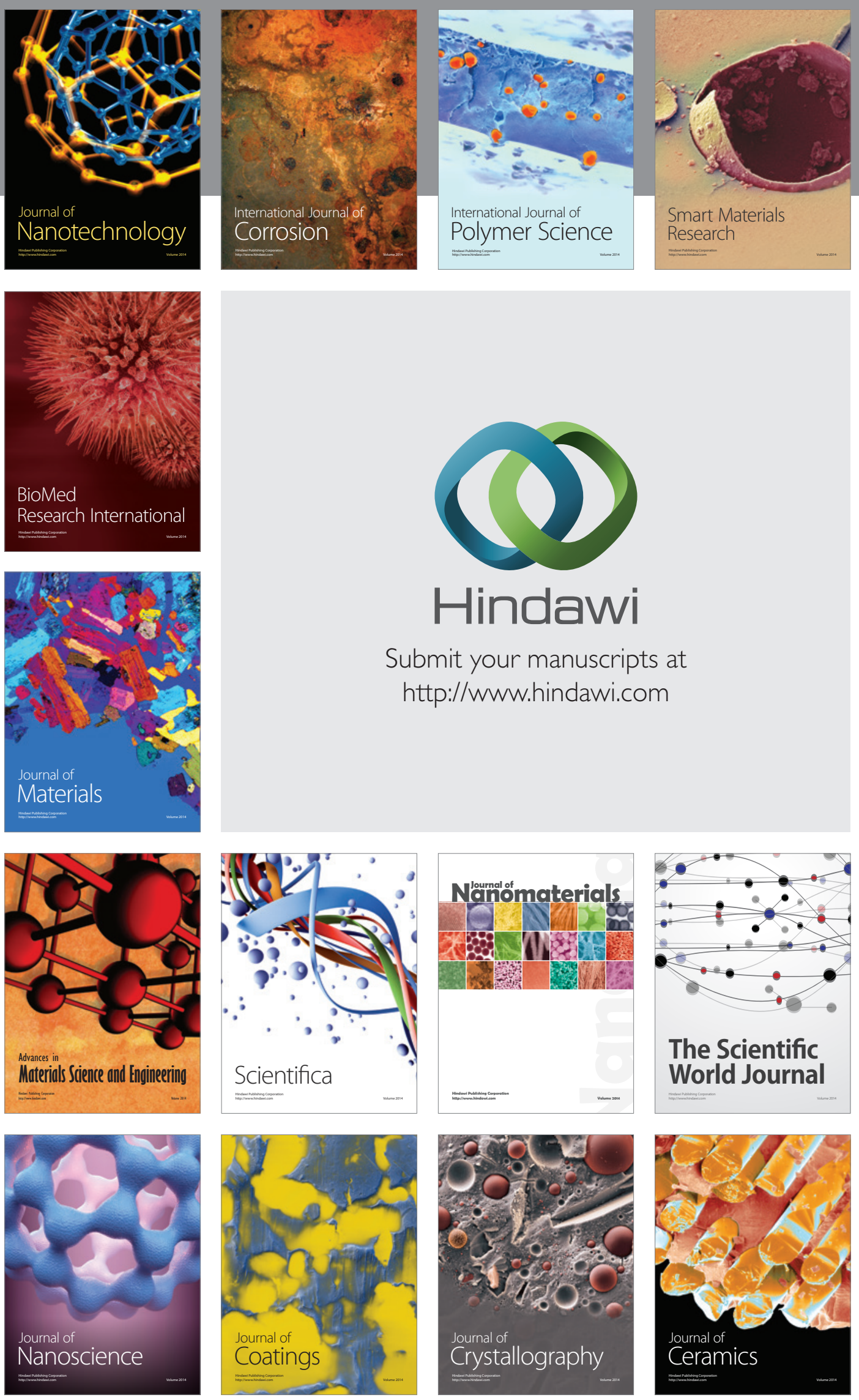

The Scientific World Journal

Submit your manuscripts at

http://www.hindawi.com

\section{World Journal}

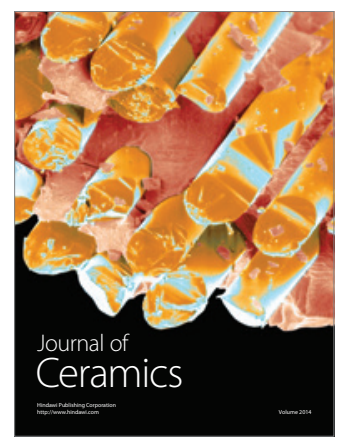

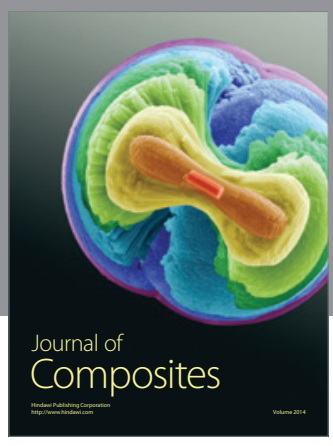
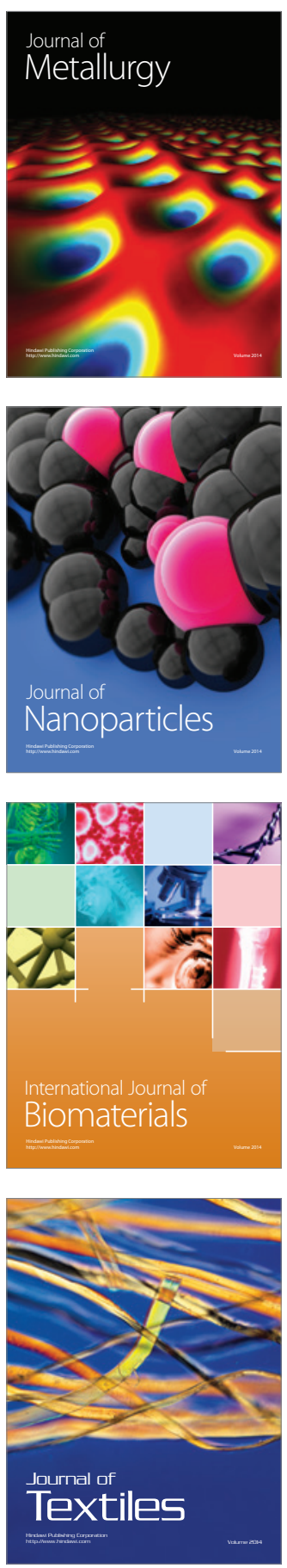